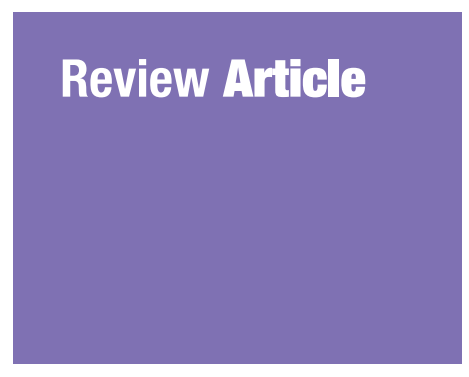

Submitted: 4 Aug 2018

Accepted: 10 Dec 2018

Online: 29 Aug 2019

\section{Advancing towards Effective Glioma Therapy: MicroRNA Derived from Umbilical Cord Mesenchymal Stem Cells' Extracellular Vesicles}

\author{
Eko Ngadiono ${ }^{1}$, Novi Silvia HardianY ${ }^{2}$
}

\author{
1 International Class Program, Faculty of Medicines Universitas Indonesia, \\ Jakarta, Indonesia \\ 2 Department of Biochemistry \& Molecular Biology, Faculty of Medicine, \\ Universitas Indonesia, Jakarta, Indonesia
}

To cite this article: Ngadiono E, Hardiany NS. Advancing towards effective glioma therapy: microrna derived from umbilical cord mesenchymal stem cells' extracellular vesicles. Malays J Med Sci. 2019;26(4):5-16. https://doi. org/10.21315/mjms2019.26.4.2

To link to this article: https://doi.org/10.21315/mjms2019.26.4.2

\begin{abstract}
A glioma, especially a grade IV glioblastoma, is a malignant tumour with a poor prognosis despite growing medical advancements. Researchers have been looking for better and more effective treatments targeting the molecular pathways of gliomas due to glioblastomas' ability to develop resistance to chemotherapies. Moreover, glioma stem cells (GSC) contribute to maintaining the glioma population, which benefits from its ability to self-renew and differentiate. Recent research has reported that through the introduction of umbilical cord mesenchymal stem cells (UCMSC) into glioma cells, the growth and development of the glioma cells can be downregulated. It has more currently been found out that UCMSC release extracellular vesicles (EVs) containing miRNA that are responsible for this phenomenon. Therefore, this review analyses literature to discuss all possible miRNAs contained within the UCMSC's EVs and to elaborate on their molecular mechanisms in halting gliomas and GSC growth. This review will also include the challenges and limitations, to account for which more in vivo research is suggested. In conclusion, this review highlights how miRNAs contained within UCMSC's EVs are able to downregulate multiple prominent pathways in the survival of gliomas.
\end{abstract}

Keywords: glioma, umbilical cord, mesenchymal stem cells, extracellular vesicles, microRNA

\section{Introduction}

A glioma is a type of cancer that arises from glial cells. In 2016, the World Health Organization (WHO) updated its terminology in categorising gliomas, which can be categorised according to the tissue from which the cancer arises, including astrocytoma, oligodendroglioma, oligoastrocytoma, and glioblastoma (1). Other than mere histological categorisation, WHO has incorporated the molecular patterns of the tissues (1). Generally, grade I has a low proliferative potential, grade II has an infiltrative nature, and grade IV is the most malignant type (1). Although grade II glioma can be resected surgically, glioma may infiltrate into other brain areas, limiting its complete removal (2). The average survival rate of patients with a grade II tumour is an average of seven years, a rate that has not been improved for the past three decades, based on previous WHO assessment due to a limited number of studies (3). Additionally, some grade II gliomas are able to advance into more malignant types of tumours, worsening the prognosis (3). Unfortunately, having a glioblastoma, a grade IV astrocytoma, is strongly associated with a poor patient outcome and with a median survival rate of approximately six months (4). Despite the advancements of cancer research 
and treatments, the outcomes, even after these treatments, remain substandard (5). These seemingly tough glioblastomas may arise due to a small number of cancer stem cells (CSC) that help in the development of gliomas (6). This small population of CSC, similar in its role to normal stem cells, allows cancer cells to proliferate as well as to differentiate into various cell phenotypes (7).

In recent years, increasing evidence has shown that the condition media of mesenchymal cells derived from umbilical cords may inhibit the cell cycle and stimulate a senescence effect on gliomas (6). This finding sheds new light on a possible method of treating gliomas, as the umbilical cord mesenchymal stem cells (UCMSC) are able to migrate towards CSC, specifically with high proliferation and low immunogenicity, making them a suitable candidate to fight against CSC (7). However, is still not known which components released by UCMSC exert an inhibitory effect on gliomas. Recently, there have been many reports that have shown microRNAs (miRNAs) possess inhibitory abilities concerning gliomas. Therefore, the inhibitory effects that have been shown by UCMSC may be due to the diverse miRNAs within UCMSC's extracellular vesicles (EVs), which affect the signal cascade pathway of the glioma (8). Thus, this review will highlight the prominent miRNAs released within UCMSC's EVs that may limit the survival of gliomas and glioma stem cells (GSC) as potential glioma treatments. Moreover, the molecular mechanisms behind glioma and GSC survival inhibition will be described.

\section{Normal Functions of UCMSC's Extracellular Vesicles and MicroRNAs}

The discovery of miRNA has changed the perspective of researchers in the regulation of mRNA. Moreover, miRNAs were once considered to be inoperable, noncoding RNA. MiRNAs are single-stranded RNA with a length of approximately $\sim 22$ nucleotides (9). RNA polymerase II within the nucleus helps in the formation of a unique stem-loop structure, called pri-miRNA, through transcription (10). The structure of pri-miRNA is similar to general mRNA, as it is equipped with a $5^{\prime}$ cap and a poly-A-tail (11); additionally, and it is cleaved by the RNAse III endonuclease attached to the microprocessor (DGCR8/DROSHA) complex in the nucleus, leaving only around
65-70 nucleotide structures, called precursormiRNAs (pre-miRNAs) (11). This processing of pre-miRNAs by the microprocessor is closely regulated by the Smad (11). The resulting premiRNAs are transported out of the nucleus through the nuclear exporting factor 5 (EXP 5) (12). Once pre-miRNAs arrive in the cytoplasm, the RNAse III endonuclease component of another protein, called Dicer, working together with TARBP2 and PRKRA, cleaves pre-miRNAs into miRNAs (13). The resulting double-stranded miRNAs are separated into two: a guide strand, which will attach to RNA-induced silencing complexes (RISC), and a passenger strand, which will be discarded (10). RISC-carrying, mature miRNAs will detect 3' untranslated regions (UTR) of their complementary strands and repress the target mRNA translation, the mRNA degradation, or both (9). Similar to other nuclear regulation, the expressions of miRNAs are also affected by epigenetic aspects, such as DNA methylation as well as histone modifications (10). In general, miRNAs work through posttranscription control, limiting the mRNAs to be translated.

UCMSC secrete multiple cytokines as well as EVs to communicate with neighbouring cells in a paracrine manner $(14,15)$. Cytokines are proteins that are freely secreted to the extracellular environment and that bind to a cell's receptor. On the other hand, EVs serve as a vehicle that protects vulnerable compounds, such as RNA or protein, from the extracellular environment. The released EVs from the donor cells can be taken by recipient cells through endocytosis, delivering the contained materials into the recipient cell's cytosol or intracellular organelles (9). Interestingly, EVs secreted by UCMSC contain miRNAs, for which the complementary bases are located within gliomas, negating RNAs' potent effect for gliomas' survival $(16,17)$. Recently, a range of miRNAs within UCMSC's EVs were discovered (14). However, the full mechanism of how EVs are endocytosed into gliomas is yet unknown. Furthermore, the mechanism of the released miRNAs that search for their complementary mRNAs within gliomas is also unknown. Nevertheless, evidence has shown that EVs from UCMSC were successfully internalised by gliomas through a distinct mechanism, inhibiting proliferation and stimulating gliomas' apoptosis in vitro (18). Multiple types of miRNAs (as shown in Table 1) and their proposed mechanisms within gliomas will be described below. 
Review Article | MicroRNA derived from UCMSC for glioma therapy

Table 1. Inhibitory effect of microRNA derived from UCMSC's EVs against glioma

\begin{tabular}{|c|c|c|c|c|c|}
\hline $\begin{array}{l}\text { Potential } \\
\text { miRNA }\end{array}$ & $\begin{array}{l}\text { Downregulated } \\
\text { pathway }\end{array}$ & $\begin{array}{l}\text { Downregulated } \\
\text { components }\end{array}$ & Potential cells & Potential outcome & Reference \\
\hline miR-199a-3p & Akt-mTOR pathway & $\begin{array}{l}\text { mTOR, Akt, and } \\
\text { P7oS6K }\end{array}$ & Glioblastoma & $\begin{array}{l}\text { Reduced proliferation, } \\
\text { autophagy }\end{array}$ & $(16,17,19)$ \\
\hline $\operatorname{miR}-410$ & - & MET & $\begin{array}{l}\text { Glioblastoma, } \\
\text { GSC }\end{array}$ & $\begin{array}{l}\text { Sensitising to ionising } \\
\text { radiation }\end{array}$ & $(29,30,33)$ \\
\hline \multirow[t]{2}{*}{$\operatorname{miR}-146 a$} & \multirow[t]{2}{*}{$\begin{array}{l}\text { EGFR signalling } \\
\text { pathway }\end{array}$} & $\begin{array}{l}\text { Notch1 protein, P13K, } \\
\text { K-Ras, Cyclin D1, and } \\
\text { MMP9 }\end{array}$ & \multirow[t]{2}{*}{ Glioma, GSC } & \multirow[t]{2}{*}{$\begin{array}{l}\text { Decreased in } \\
\text { aggressiveness }\end{array}$} & \multirow[t]{2}{*}{$(34,35)$} \\
\hline & & $\begin{array}{l}\text { inhibiting Akt } \\
\text { phosphorylation }\end{array}$ & & & \\
\hline Let-7b & NF-kB & $\begin{array}{l}\text { E2F2, Cyclin D1, } \\
\text { IKBKE }\end{array}$ & $\begin{array}{l}\text { Glioblastoma, } \\
\text { GSC }\end{array}$ & $\begin{array}{l}\text { Reduced growth and } \\
\text { migration }\end{array}$ & $\begin{array}{l}(45,47,48, \\
49)\end{array}$ \\
\hline miR-181 family & Cell cycle & CyclinB1 & $\begin{array}{l}\text { Glioma, } \\
\text { Glioblastoma }\end{array}$ & $\begin{array}{l}\text { Reduced proliferation, } \\
\text { autophagy }\end{array}$ & $(34,55)$ \\
\hline miR-181a & EGFR/P13K/Akt & Notch 2, Bcl-2 & $\begin{array}{l}\text { Glioblastoma, } \\
\text { GSC }\end{array}$ & $\begin{array}{l}\text { Sensitising to ionising } \\
\text { radiation }\end{array}$ & $(57,59)$ \\
\hline miR-181b & MAPK, NF-kB & $\begin{array}{l}\text { MEK1, MDM2, } \\
\text { KPNA4 }\end{array}$ & $\begin{array}{l}\text { GSC, } \\
\text { Glioblastoma }\end{array}$ & $\begin{array}{l}\text { Sensitising to } \\
\text { temozolomide and } \\
\text { teniposide }\end{array}$ & $\begin{array}{l}(61,62,63, \\
65)\end{array}$ \\
\hline \multirow[t]{2}{*}{ miR-181c } & \multirow[t]{2}{*}{$\begin{array}{l}\text { TGF- } \beta \text { downstream } \\
\text { pathways }\end{array}$} & $\begin{array}{l}\text { Notch2, N-cadherin, } \\
\text { Vimentin }\end{array}$ & \multirow[t]{2}{*}{ Glioblastoma } & \multirow[t]{2}{*}{ Decreased in invasiveness } & \multirow[t]{2}{*}{$(66,67)$} \\
\hline & & $\begin{array}{l}\text { Upregulated } \\
\text { E-cadherin }\end{array}$ & & & \\
\hline miR-181d & $\begin{array}{l}\text { MAPK/ERK and } \\
\text { P13K/AKT }\end{array}$ & MGMT, K-ras, Bcl-2 & Glioblastoma & $\begin{array}{l}\text { Decreased glioblastoma } \\
\text { growth in vivo, sensitising } \\
\text { to temozolomide }\end{array}$ & $(44,71)$ \\
\hline $\operatorname{miR}-145$ & - & ABCG2, ADAM19 & $\begin{array}{l}\text { GSC, } \\
\text { glioblastoma }\end{array}$ & $\begin{array}{l}\text { Sensitising to } \\
\text { temozolomide, reduced } \\
\text { invasion }\end{array}$ & $(17,72,77)$ \\
\hline
\end{tabular}

MicroRNAs, Found within UCMSCs' EVs, Downregulate Essential Gliomas and Glioma Stem Cells' Molecular Pathways

\section{MiR-199a-3p limits glioblastoma survival through the AKT-mTOR pathway, leading to Survivin's downregulation}

Though UCMSC's EVs do not contain miR-199a-3p specifically, they contain its precursor, miR-199a (17). It has been shown that glioblastomas, introduced with miR199a-3p, reveal low overall proliferation and low expression of proteins in the AKT-mTOR pathway, including mTOR, AKT and P7OS6K (16). The downregulation of protein in this AKTmTOR pathway initiates the glioma autophagy mechanism (19). Furthermore, AKT-mTOR downstream signalling will eventually lead to a potent protein called Survivin (20).

Survivin is present in highly divisive cells, such as developing embryos and, unfortunately, cancer (21). However, it is less likely to locate Survivin in terminally differentiated cells (21). The increased expression of Survivin worsens the outcome of gliomas (22). Addressing Survivin as potential therapeutic target slows the progression of gliomas by inhibiting invasion and reducing their proliferation rate (23). Moreover, suppressing Survivin is correlated with decreased resistance to chemotherapy and radiation therapy $(24,25)$. Survivin is critical in affecting gliomas' survival due to its dual functions, that is, cell division and its effect on regulating caspase 9 (the internal apoptosis pathway) (26, 27). It can be said that damage to Survivin's ability in a normal cell will lead normal cells into malignancies in agreement with the two hallmarks of cancer, resisting apoptosis and the cell's ability to proliferate indefinitely (28). Therefore, the effort in blocking the upstream pathway of Survivin, the AKT-mTOR pathway, is crucial in limiting the aggressiveness of gliomas. 
MiR-41O inhibition of GSC and the survival of glioblastomas through MET

MET is a hepatocyte growth receptor (HGR), and upon binding of the hepatocyte growth factor, phosphorylates AKT to prevent cell apoptosis through the inhibition of caspase (29). It was further shown that MET regulates the signalling system of GSC by increasing their proliferation, migration rate, and almost all critical survival ability (30). UCMSC contain miR-410 within their EVs (31). The various outcomes in transferring miR-410 have been in conflict. Moreover, the over-expression of miR410 has been shown to increase the survival of lung adenocarcinoma, liver and colorectal cancer $(31,32)$. In contrast, the introduction of miR410 into a glioblastoma results in suppressing the growth of the glioblastoma by inhibiting the expression of MET (33). Moreover, the downregulation of MET sensitises the GSC to ionising radiation (29). Thus, the downregulation of MET may be a prominent solution, as it suppresses the aggressiveness of the GSC and glioblastomas in any aspects.

\section{MiR-146a inhibition of the growth of gliomas and GSC through Notch1 signalling}

An analysis was performed by $\mathrm{Ti}$ et al. to estimate the miRNAs in the EVs of UCMSC, comparing them to the EVs of human fibroblasts (34). It showed that three miRNAs were upregulated where only two miRNAs were described, miR-146a and miR-181 (34). The exposure of miR-146a prevents malignant astrocytes from being turned into GSC (35). It has been shown that miR-146a targets the expression of the Notch1 protein, which is often over-expressed in gliomas and glioblastomas, by downregulating its transcription pathway and, consequently, reducing the epidermal growth factor receptor (EGFR) downstream pathway activities $(35,36)$. EGFR is often amplified and over-expressed in cancer cells and, unexceptionally, in gliomas (37). Moreover, around half of the over-expressed EGFR are found to express the mutant EGFRvIII variant, resulting in the failure of ligand binding and autophosphorylation $(38,39)$. Neither the expression of EGFRvIII nor the over-expression of EGFR decreases the aggressiveness of gliomas $(40,41)$. One of the reasons for this may be that the constitutive activation of EGFRvIII and over-expressed EGFR in gliomas activates the downstream pathways that play an essential role in promoting the survival of gliomas through
STAT3, MAPK and AKT (42). AKT activation is more prominent in both cases while $\mathrm{STAT}_{3}$ and MAPK activation varies (42).

As aforementioned, activated AKT shares a part in guiding the multiple pathways responsible for the malignant behaviour of gliomas. MiR-146a generates an anti-glioma effect by preventing AKT from becoming phosphorylated (36). In addition, evidence has shown that miR-146a is able to suppress other EGFR downstream pathways, including $\mathrm{PI}_{3} \mathrm{~K}$, $\mathrm{K}-\mathrm{Ras}$, cyclin D1 and MMP9 (35). $\mathrm{PI}_{3} \mathrm{~K}$ is an upstream component of a complex network responsible for activating AKT as well as mTOR (43). Eventually, the activation of $\mathrm{PI}_{3} \mathrm{~K}$ will promote growth and inhibit apoptosis in gliomas (43). Activated $k$-Ras will eventually lead to PI3K/AKT, NF-kB and ERK signalling pathways (44). Similarly, its aberrant activation is also associated with carcinogenesis (44). Part of Cyclin D1's function is regulating the cell cycle. Downregulating Cyclin D1 has been shown to be effective in halting cell proliferation and promoting apoptosis when cisplatin was administered (45). Lastly, MMP9 is a component of the matrix metalloproteinases (MMP) family, which is responsible in degrading the extracellular matrix (46). MMP9 has been speculated to be responsible for the invasion of gliomas; furthermore, high expression of MMP9 is correlated with high cell growth and has been shown to be highly present in more aggressive types of gliomas (46).

\section{Let-7b suppression of GSC and glioblastomas through the regulation of cell cycle components and apoptosis}

Previously, UCMSC treated with lipopolysaccharide were found to contain Let$7 \mathrm{~b}$ in their EVs (47). Let-7b is responsible for halting the growth and migration of glioblastomas and GSC by directly targeting the 3' UTR region of E2F2, a transcription factor responsible in the cell cycle and tumorigenesis (48). The over-expression of Let-7b also suppresses cyclin D1 protein expression in glioblastomas (45). Lastly, Let-7b downregulates a distinct component called the inhibitor of the nuclear factor kappa-B kinase subunit epsilon (IKBKE) in glioblastomas (49). IKBKE is often found to be over-expressed in gliomas and is believed to play a role in inhibiting apoptosis through the NF-kB pathway (50). Furthermore, IKBKE activates NF-kB by phosphorylating its inhibitor, the inhibitor kappa B (50). The NF-kB 
pathway is very complex and is responsible for various cell controls (51). NF-kB downregulation has also been associated with suppressed vascular endothelial growth factor (VEGF) and IL-8, a component and cytokine, respectively, responsible for angiogenesis (52). Therefore, Let$7 \mathrm{~b}$ is potent in downregulating NF-kB through IKBKE. Nevertheless, research has shown that IKBKE and Let-7b are components of the regulatory feedback loop in which a decrease of one component will increase the other (53). Thus, instead of downregulation, research has suggested a block of the circuit as a method for glioblastoma treatment (53).

\section{MiR-181 family targeting of multiple cellular pathways in glioblastomas and GSC}

As previously mentioned, mir-181 was upregulated within UCMSC's EVs (34). However, it was not mentioned which miR181 members were upregulated. Therefore, each of the members will be discussed herein as each member presents potential as a glioma treatment. The miR-181 family contains four members, including miR-181a, miR-181b, miR$181 \mathrm{c}$ and miR-181d (54). In general, miR-181 oligonucleotide targets cyclin B1 3' UTR and downregulates its expression in gliomas and glioblastomas (55). Cyclin B1 is important for cell cycle progression and is often dysregulated in gliomas (56).

MiR-181a targets the 3' UTR region of Notch2 in glioblastomas (57). The downregulation of Notch2 was reported to exert the same outcome as the downregulation of Notch1 (58). Notch2 was also suspected of participation in the EGFR/P13K/AKT pathway in conjunction with Notch1 (58). However, the exact mechanism of Notch-2 in gliomas is still debatable (57). The over-expression of Notch2 stimulates the malignancy of gliomas and GSC while the introduction of mir-181a successfully inhibits them (57). Another study confirmed miR-181a as a potential glioblastoma treatment by sensitising the glioblastomas to radiation through B-cell lymphoma 2 protein (Bcl-2) downregulation, an anti-apoptotic protein (59, $60)$.

MiR-181b sensitises gliomas and GSC to various chemotherapies, such as temozolomide and teniposide, by targeting the 3' UTRs of both MDM2 and MEK1, respectively (61-63). MEK1 is one component in the MAPK pathway, a pathway that is often highly expressed in gliomas responsible for regulating cell apoptosis, proliferation, and resistance to chemotherapy (61). Often over-expressed in glioblastomas (64), MDM2 is an E3 ubiquitin ligase that degrades a tumour's suppressor protein, called p53 (64). MiR-181b suppresses phosphorylated MDM2, reverting p53 degradation and sensitising gliomas to teniposide (62). Other research has discovered that miR-181b downregulates KPNA4 in glioblastomas, a protein within an elaborate pathway that is responsible for activating NF$\mathrm{kB}(65)$. As mentioned previously, aberrant NF$\mathrm{kB}$ is often correlated with the proliferation of gliomas, in which its expression is best kept in control. MiR-181b was also shown to suppress glioblastoma growth in vivo (65).

MiR-181c is highly responsible in controlling the invasion and proliferation of gliomas. Similar to miR-181a, miR-181c has been suspected of binding at Notch2 UTRs, downregulating its expression (66). MiR181c inhibits the epithelial-mesenchymal transition (EMT) of glioblastomas through the downregulation of N-cadherin and Vimentin while E-cadherin is upregulated (67). EMT is a term that refers to when epithelial cells lose their adhesion and migrate out as mesenchymal cells (68). It is considered a factor for glioma invasiveness (68). Furthermore, the involvement of E/N-cadherin is closely related to the EMT of gliomas. E-cadherin is rarely expressed in gliomas, whereas $\mathrm{N}$-cadherin expression is often upregulated (68). Meanwhile, the overexpression of Vimentin has resulted in the increased growth of gliomas, as it is believed to act as a chaperone for various protein kinases (69). It has been further concluded that TGF- $\beta$ plays an essential role in controlling glioma invasion, in which miR-181c is able to inhibit its downstream pathway (67). TGF- $\beta$ is a cytokine of which the downstream pathway is associated with proliferation, angiogenesis, invasion, and immunosuppression (70). Even worse, gliomas actively secrete TGF- $\beta$, self-facilitating its growth (70). Therefore, blocking TGF- $\beta$ cytokine activity poses a great advantage for the treatment advancement of gliomas.

MiR-181d has been reported to bind directly to methyl-guanine-methyl-transferase (MGMT) 3' UTR, sensitising glioblastomas to temozolomide (71). MGMT is a protein responsible for repairing TMA-induced DNA damage that leads to temozolomide therapy failure (71). Furthermore, miR-181d suppresses multiple signalling activities, which include MAPK/ERK and P13K/AKT pathways through 
K-ras activation (44). MiR-181d directly targets the 3' UTR of K-ras and Bcl-2 (44). As previously discussed, these pathways and components are essential for glioma tumourigenesis. Moreover, miR-181d even successfully inhibits the growth of glioblastomas in vivo (44).

MiR-145 limitation of GSC and GBM aggressiveness by ABCG2 and ADAM19, respectively.

MiR-145 has been found to be contained in UCMSC's EV's (17), and it serves as a potent regulator in downregulating the ATP-binding cassette, sub-family G, member 2 (ABCG2) expressions in GSC (72). It is widely known that ABCG2 is a transporter protein that transports xenobiotic drugs out from tumour cells. An important factor, GSC is resistant to multiple chemotherapeutic drugs (73). Another study reported that by downregulating ABCG2, GSC are more vulnerable to temozolomide (74). Moreover, ABCG2 serves as one factor of gliomas' stemness and roles in invasion as well as migration $(75,76)$. MiR-145 directly targets ADAM19 3' UTR downregulating a glioblastoma's ability for EMT (77). The resulting expression of N-cadherin, E-cadherin, and Vimentin show similar results when miR-181c is introduced (77).

\section{Multiple miRNAs obtained in UCMSC EVS potentiate gliomas' survival}

Gliomas are known to express multiple kinds of cytokines to enhance their survival and migration. However, other than expressing cytokines benefiting their own growth, it was also discovered that gliomas release miRNAs, found in the serum of patients' blood (78). MiRNAs released by gliomas may affect important regulations in many biological processes. Therefore, a full range of miRNAs were addressed, and their expressions were calculated. Several miRNAs, such as miR-1252, miR-4434, and miR-4669, have been found to be upregulated significantly (78). Interestingly, these miRNAs are also found within UCMSC's EVs in their primary form (14). However, less is known concerning their function in the development of gliomas' survival, let alone their molecular mechanisms. It is therefore suggested to conduct more research on these miRNAs as they pose a potential treatment or threat to gliomas.

\section{Perspectives and Challenges}

MiRNAs contained within UCMSC's EVs pose a promising prospect as a treatment for gliomas in the future. The UCMSC's EVs are equipped with diverse miRNAs that inhibit multiple downstream pathways accountable for gliomas as well as GSC survival. These miRNAs regulate cell signalling that is important for proliferation, angiogenesis, invasion, chemotherapy effectiveness, and apoptosis. Furthermore, prominent signalling components and pathways that are often over-expressed in gliomas, such as MAPK/ERK, P13K/AKT, MAPK and cell cycle regulators, were downregulated. Each miRNA possesses capabilities in inhibiting gliomas through various pathways that will intersect eventually and amplify the inhibition effects of miRNAs. In addition to inhibiting prominent pathways, some miRNAs inhibit the same components of gliomas' aggressiveness, including Notch2, Bcl-2, K-ras and the AKT protein. In addition, an miRNA is not only released by UCMSC within the extracellular vesicle, but a range of miRNAs are also released by certain types of cancer (12). Certain cancers release unique profiles of miRNAs that differ from one cancer cell to another (12). Therefore, miRNAs can not only be used for treatment purposes by suppressing over-reactive cancer cells' mRNAs, but they can also be used as cancer biomarkers for diagnostic purposes (12).

Nevertheless, there are still challenges needing to be solved in using UCMSC as a future treatment for gliomas. Cytokines released by UCMSC function as growth factor for gliomas instead of restricting them, for example, IL-6, GRO, MCP-1 and IL-8 (7). IL-6 activates the JAK/STAT3 pathway in human gliomas, an activation that is correlated with the proliferation and invasion of gliomas (79). However, the JAK/STAT3 pathway is not regulated through any identified miRNAs derived from UCMSC's EVs. GBM exerts the IL-8 autocrine mechanism and expresses a high number of IL-8 receptors, such as CXCR1 and CXCR2 (80). Therefore, IL-8 is suspected to be a potent regulator in glioma survival. Moreover, it was reported that IL-8 plays a certain part in regulating NF-kB in gliomas (80). In this case, though miRNAs inhibit NF-kB through the downregulation of IKBKE, the downstream mechanism of IL-8 should be taken into consideration. Meanwhile, the detailed molecular mechanism involving MCP-1 and GRO in gliomas is still unclear. 
More research still needs to be conducted considering many factors that may affect miRNAs' efficacy derived from UCMSC's EVs as a treatment for gliomas. The research reviewed in this article was performed only by introducing a type of miRNA. None of the research performed introduced multiple miRNAs to measure the outcome. Therefore, it is suggested to perform more research in the future to understand the inter-communication between multiple miRNAs in gliomas, reflecting the actual settings of UCMSC's EVs' delivery. Furthermore, in vivo research and clinical studies are suggested. Also, the outcome preceding miRNAs' delivery might differ depending on which glioma cell lines are used. Last but not least, the majority of glioma tissues used for miRNAs quantification are collected and performed in mainland China. Therefore, it is suggested that researchers planning to perform similar research take genetic bias into consideration.

\section{Conclusion}

This review summarises a range of potential miRNAs as glioma treatments contained within UCMSC's EVs. Additionally, this review highlights the utilisation of these miRNAs in inhibiting multiple prominent signalling pathways responsible for overall glioma and GSCs' survival, proposing this method as an effective glioma treatment in the future.

\section{Acknowledgements}

The authors thank the Direktorat Riset \& Pengabdian Masyarakat Universitas Indonesia (DRPM) for funding the Publikasi Terindeks untuk Tugas Akhir Mahasiswa Universitas Indonesia (PITTA UI 2018).

\section{Conflict of Interest}

None.

\section{Funds}

Grant number: 2106/UN2.R3.1/ HKP.05.00/2018.

\section{Authors' Contributions}

Conception and design: EN

Analysis and interpretation of the data: EN

Drafting of the article: EN

Critical revision of the article for the important

intellectual content: NSH

Final approval of the article: NSH

Obtaining of funding: $\mathrm{NSH}$

\section{Correspondence}

Dr Novi Silvia Hardiany

$\mathrm{PhD}$ (Universitas Indonesia), MBiomed (Universitas Indonesia)

Department of Biochemistry \& Molecular Biology, Faculty of Medicine Universitas Indonesia,

Jalan Salemba Raya no. 6, Jakarta 10430,

Indonesia.

Tel: +62213910734

Fax: +62213910190

E-mail: novi.silvia@ui.ac.id, novish98@gmail.com

\section{References}

1. Louis DN, Perry A, Reifenberger G, von Deimling A, Figarella-Branger D, Cavenee WK, et al. The 2016 World Health Organization classification of tumors of the central nervous system: a summary. Acta Neuropathol. 2016;131(6):803-820. https://doi.org/10.1007/s00401-016-1545-1

2. Ho VKY, Reijneveld JC, Enting RH, Bienfait HP, Robe P, Baumert BG, et al. Changing incidence and improved survival of gliomas. Eur $J$ Cancer. 2014;50(13):2309-2318. https://doi. org/10.1016/j.ejca.2014.05.019

3. Claus EB, Walsh KM, Wiencke JK, Molinaro AM, Wiemels JL, Schildkraut JM, et al. Survival and low-grade glioma: the emergence of genetic information. Neurosurg Focus. 2015;38(1):E6. https://doi.org/10.3171/2014.10.FOCUS12367

4. Brodbelt A, Greenberg D, Winters T, Williams M, Vernon S, Collins VP, et al. Glioblastoma in England: 2007-2011. Eur $J$ Cancer. 2015;51(4):533-542. https://doi.org/10.1016/j. ejca.2014.12.014

5. Ahmadloo N, Kani A-A, Mohammadianpanah M, Nasrolahi H, Omidvari S, Mosalaei A, et al. Treatment outcome and prognostic factors of adult glioblastoma multiforme. $J$ Egypt Natl Canc Inst. 2013;25(1):21-30. https://doi. org/10.1016/j.jnci.2012.11.001 
6. Kološa K, Motaln H, Herold-Mende C, Koršič M, Lah TT. Paracrine effects of mesenchymal stem cells induce senescence and differentiation of glioblastoma stem-like cells. Cell Transplant. 2015;24(4):631-644. https://doi. org/10.3727/096368915X687787

7. Bajetto A, Pattarozzi A, Corsaro A, Barbieri F, Daga A, Bosio A, et al. Different effects of human umbilical cord mesenchymal stem cells on glioblastoma stem cells by direct cell interaction or via released soluble factors. Front Cell Neurosci. 2017;11:312. https://doi.org/10.3389/ fncel.2017.00312

8. Yang C, Lei D, Ouyang W, Ren J, Li H, Hu J, et al. Conditioned media from human adipose tissue-derived mesenchymal stem cells and umbilical cord-derived mesenchymal stem cells efficiently induced the apoptosis and differentiation in human glioma cell lines in vitro. Biomed Res Int. 2014;2014:1-13. https://doi. org/10.1155/2014/109389

9. Rodini CO, Gonçalves da Silva PB, Assoni AF, Carvalho VM, Okamoto OK. Mesenchymal stem cells enhance tumorigenic properties of human glioblastoma through independent cellcell communication mechanisms. Oncotarget. 2018;9(37):24766-24777. https://doi. org/10.18632/oncotarget.25346

10. Zou X-Y, Yu Y, Lin S, Zhong L, Sun J, Zhang G, et al. Comprehensive miRNA analysis of human umbilical cord-derived mesenchymal stromal cells and extracellular vesicles. Kidney Blood Press Res. 2018;43(1):152-161. https://doi. org/10.1159/000487369

11. Dabrowski FA, Burdzinska A, Kulesza A, Sladowska A, Zolocinska A, Gala K, et al. Comparison of the paracrine activity of mesenchymal stem cells derived from human umbilical cord, amniotic membrane and adipose tissue. J Obstet Gynaecol Res. 2017;43(11):17581768. https://doi.org/10.1111/jog.13432

12. Aranda JF, Canfrán-Duque A, Goedeke L, Suárez Y, Fernández-Hernando C. The miR-199-dynamin regulatory axis controls receptor-mediated endocytosis. $J$ Cell Sci. 2015;128(17):3197-3209. https://doi. org/10.1242/jcs.165233
13. Shen L, Sun C, Li Y, Li X, Sun T, Liu C, et al. MicroRNA-199a-3p suppresses glioma cell proliferation by regulating the AKT/ mTOR signaling pathway. Tumor Biol. 2015;36(9):6929-6938.https://doi.org/10.1007/ s13277-015-3409-Z

14. Qian X, Xu C, Fang S, Zhao P, Wang Y, Liu H, et al. Exosomal microRNAs derived from umbilical mesenchymal stem cells inhibit Hepatitis C virus infection. Stem Cells Transl Med. 2016;5(9):1190-1203. https://doi.org/10.5966/ sctm.2015-0348

15. Shi L, Wang Z, Sun G, Wan Y, Guo J, Fu X. miR145 inhibits migration and invasion of glioma stem cells by targeting ABCG2. NeuroMolecular Med. 2014;16(2):517-528. https://doi. org/10.1007/s12017-014-8305-y

16. Søkilde R, Newie I, Persson H, Borg Å, Rovira C. Passenger strand loading in overexpression experiments using microRNA mimics. RNA Biol. 2015;12(8):787-791. https://doi.org/10.1080/15 476286.2015.1020270

17. Del Fattore A, Luciano R, Saracino R, Battafarano G, Rizzo C, Pascucci L, et al. Differential effects of extracellular vesicles secreted by mesenchymal stem cells from different sources on glioblastoma cells. Expert Opin Biol Ther. 2015;15(4):495504. https://doi.org/10.1517/14712598.2015.9977 06

18. Huang H, Song J, Liu Z, Pan L, Xu G. Autophagy activation promotes bevacizumab resistance in glioblastoma by suppressing Akt/mTOR signaling pathway. Oncol Lett. 2017;15(2):1487-1494. https://doi.org/10.3892/ol.2017.7446

19. Anandharaj A, Cinghu S, Park W-Y. Rapamycinmediated mTOR inhibition attenuates survivin and sensitizes glioblastoma cells to radiation therapy. Acta Biochim Biophys Sin. 2011;43(4):292-300. https://doi.org/10.1093/ abbs/gmro12

20. Noel JP, Verdecia MA, Huang H, Dutil E, Kaiser DA, Hunter T. Structure of the human antiapoptotic protein survivin reveals a dimeric arrangement. Nat Struct Biol. 2000;7(7):6026o8. https://doi.org/10.1038/76838

21. Zhang S, Zhang C, Song $\mathrm{Y}$, Zhang J, Xu J. Prognostic role of survivin in patients with glioma. Medicine. 2018;97(17):e0571. https:// doi.org/10.1097/MD.0000000000010571 
22. Guo H, Wang $Y$, Song $\mathrm{T}$, Xin $\mathrm{T}$, Zheng $\mathrm{Z}$, Zhong $\mathrm{P}$, et al. Silencing of Survivin using YM155 inhibits invasion and suppresses proliferation in glioma cells. Cell Biochem Biophys. 2015;71(2):587-593. https://doi.org/10.1007/s12013-014-0238-4

23. Yanbo L, Chunming M, Zhenjiang W, Xin H, Weigao S. Survivin small interfering RNA suppresses glioblastoma growth by inducing cellular apoptosis. Neural Regen Res. 2012;7(12):924-931. https://doi.org/10.3969/j. issn.1673-5374.2012.12.008

24. Cruz RQ, Morais CM, Cardoso AM, Silva SG, Vale ML, Marques EF, et al. Enhancing glioblastoma cell sensitivity to chemotherapeutics: A strategy involving survivin gene silencing mediated by gemini surfactant-based complexes. Eur $J$ Pharm Biopharm. 2016;104:7-18. https://doi. org/10.1016/j.ejpb.2016.04.014

25. Chakravarti A, Zhai GG, Zhang M, Malhotra R, Latham DE, Delaney MA, et al. Survivin enhances radiation resistance in primary human glioblastoma cells via caspase-independent mechanisms. Oncogene. 2004;23(45):74947506. https://doi.org/10.1038/sj.onc.1208049

26. Tang T-K, Chiu S-C, Lin C-W, Su M-J, Liao M-H. Induction of survivin inhibition, $\mathrm{G}_{2} / \mathrm{M}$ cell cycle arrest and autophagic on cell death in human malignant glioblastoma cells. Chin $J$ Physiol. 2015;58(2):95-103. https://doi.org/10.4077/ CJP.2015.BAC267

27. Zhang $\mathrm{H}, \mathrm{Xu} \mathrm{F}$, Xie $\mathrm{T}$, Jin $\mathrm{H}$, Shi $\mathrm{L}$. $\beta$-elemene induces glioma cell apoptosis by downregulating survivin and its interaction with hepatitis B X-interacting protein. Oncol Rep. 2012;28(6):2083-2090. https://doi. org/10.3892/or.2012.2022

28. Hanahan D, Weinberg RA. Hallmarks of cancer: the next generation. Cell. 2011;144(5):646-674. https://doi.org/10.1016/j.cell.2011.02.013

29. De Bacco F, D’Ambrosio A, Casanova E, Orzan F, Neggia R, Albano R, et al. MET inhibition overcomes radiation resistance of glioblastoma stem-like cells. EMBO Mol Med. 2016;8(5):550568. https://doi.org/10.15252/emmm.201505890

30. Joo KM, Jin J, Kim E, Ho Kim K, Kim Y, Gu Kang $\mathrm{B}$, et al. MET signaling regulates glioblastoma stem cells. Cancer Res. 2012;72(15):3828-3838. https://doi.org/10.1158/ooo8-5472.CAN-11-376o
31. Dong L, Pu Y, Zhang L, Qi Q, Xu L, Li W, et al. Human umbilical cord mesenchymal stem cellderived extracellular vesicles promote lung adenocarcinoma growth by transferring miR410. Cell Death Dis. 2018;9(2):218. https://doi. org/10.1038/s41419-018-0323-5

32. Wang Y, Fu J, Jiang M, Zhang X, Cheng L, Xu $\mathrm{X}$, et al. MiR-410 is overexpressed in liver and colorectal tumors and enhances tumor cell growth by silencing FHL1 via a direct/indirect mechanism. PLoS One. 2014;9(10):e108708. https://doi.org/10.1371/journal.pone.0108708

33. Chen L, Zhang J, Feng Y, Li R, Sun X, Du W, et al. MiR-410 regulates MET to influence the proliferation and invasion of glioma. Int $J$ Biochem Cell Biol. 2012;44(11):1711-1717. https://doi.org/10.1016/j.biocel.2012.06.027

34. Ti D, Hao H, Fu X, Han W. Mesenchymal stem cells-derived exosomal microRNAs contribute to wound inflammation. Sci China Life Sci. 2016;59(12):1305-1312. https://doi. org/10.1007/s11427-016-0240-4

35. Mei J, Bachoo R, Zhang C-L. MicroRNA-146a inhibits glioma development by targeting Notch1. Mol Cell Biol. 2011;31(17):3584-3592. https:// doi.org/10.1128/MCB.05821-11

36. Xu P, Qiu M, Zhang Z, Kang C, Jiang R, Jia Z, et al. The oncogenic roles of Notch1 in astrocytic gliomas in vitro and in vivo. $J$ Neurooncol. 2010;97(1):41-51. https://doi.org/10.1007/ s11060-009-0007-1

37. Brennan CW, Verhaak RGW, McKenna A, Campos B, Noushmehr H, Salama SR, et al. The somatic genomic landscape of glioblastoma. Cell. 2013;155(2):462-477. https://doi.org/10.1016/j. cell.2013.09.034

38. Huang PH, Mukasa A, Bonavia R, Flynn RA, Brewer ZE, Cavenee WK, et al. Quantitative analysis of EGFRvIII cellular signaling networks reveals a combinatorial therapeutic strategy for glioblastoma. Proc Natl Acad Sci USA. 2007;104(31):12867-12872. https://doi. org/10.1073/pnas.0705158104 
39. Felsberg J, Hentschel B, Kaulich K, Gramatzki D, Zacher A, Malzkorn B, et al. Epidermal growth factor receptor variant III (EGFRvIII) positivity in eGFR-amplified glioblastomas: prognostic role and comparison between primary and recurrent tumors. Clin Cancer Res. 2017;23(22):68466855. https://doi.org/10.1158/1078-0432.CCR$17-0890$

40. Stec WJ, Rosiak K, Siejka P, Peciak J, Popeda M, Banaszczyk M, et al. Cell line with endogenous EGFRvIII expression is a suitable model for research and drug development purposes. Oncotarget. 2016;7(22):31907-31925. https:// doi.org/10.18632/oncotarget.8201

41. Verhaak RGW, Hoadley KA, Purdom E, Wang V, Qi Y, Wilkerson MD, et al. Integrated genomic analysis identifies clinically relevant subtypes of glioblastoma characterized by abnormalities in PDGFRA, IDH1, EGFR, and NF1. Cancer Cell. 2010;17(1):98-110. https://doi.org/10.1016/j. ccr.2009.12.020.

42. Mizoguchi M, Betensky RA, Batchelor TT, Bernay DC, Louis DN, Nutt CL. Activation of STAT3, MAPK, and AKT in malignant astrocytic gliomas. $J$ Neuropathol Exp Neurol. 2006;65(12):11811188. https://doi.org/10.1097/o1. jnen.0ooo248549.14962.b2

43. Fan Q-W, Weiss WA. Inhibition of PI3K-AktmTOR signaling in glioblastoma by mTORC1/2 inhibitors. In Humana Press. 2012;821:349-359. https://doi.org/10.1007/978-1-61779-430-8_22

44. Wang X-F, Shi Z-M, Wang X-R, Cao L, Wang Y-Y, Zhang J-X, et al. MiR-181d acts as a tumor suppressor in glioma by targeting K-ras and Bcl-2. $J$ Cancer Res Clin Oncol. 2012;138(4):573-584. https://doi.org/10.1007/s00432-011-1114-x

45. Guo Y, Yan K, Fang J, Qu Q, Zhou M, Chen F. Let-7b expression determines response to chemotherapy through the regulation of Cyclin D1 in glioblastoma. $J$ Exp Clin Cancer Res. 2013;32(1):41. https://doi.org/10.1186/17569966-32-41

46. Xue Q, Cao L, Chen X-Y, Zhao J, Gao L, Li S-Z, et al. High expression of MMP9 in glioma affects cell proliferation and is associated with patient survival rates. Oncol Lett. 2017;13(3):1325-1330. https://doi.org/10.3892/ol.2017.5567
47. Ti D, Hao H, Tong C, Liu J, Dong L, Zheng J, et al. LPS-preconditioned mesenchymal stromal cells modify macrophage polarization for resolution of chronic inflammation via exosome-shuttled let-7b. $J$ Transl Med. 2015;13:308. https://doi. org/10.1186/s12967-015-0642-6

48. Song H, Zhang Y, Liu N, Zhang D, Wan C, Zhao $\mathrm{S}$, et al. Let-7b inhibits the malignant behavior of glioma cells and glioma stem-like cells via downregulation of E2F2. $J$ Physiol Biochem. 2016;72(4):733-744. https://doi.org/10.1007/ s13105-016-0512-6

49. Tian Y, Hao S, Ye M, Zhang A, Nan Y, Wang $\mathrm{G}$, et al. MicroRNAs let-7b/i suppress human glioma cell invasion and migration by targeting IKBKE directly. Biochem Biophys Res Commun. 2015;458(2):307-312. https://doi.org/10.1016/j. bbrc.2015.01.105

50. Guan $\mathrm{H}$, Zhang $\mathrm{H}$, Cai J, Wu J, Yuan J, Li $\mathrm{J}$, et al. IKBKE is over-expressed in glioma and contributes to resistance of glioma cells

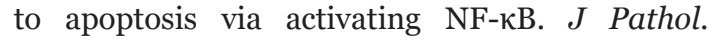
2011;223(3):436-445. https://doi.org/10.1002/ path. 2815

51. Jiang G, Zhang L, Wang J, Zhou H. Baicalein induces the apoptosis of U251 glioblastoma cell lines via the NF-kB-p65-mediated mechanism. Animal Cells Syst. 2016;20(5):296-302. https:// doi.org/10.1080/19768354.2016.1229216

52. Xie T-X, Xia Z, Zhang N, Gong W, Huang S. Constitutive NF-kappaB activity regulates the expression of VEGF and IL-8 and tumor angiogenesis of human glioblastoma. Oncol Rep. 2010;23(3):725-732. https://doi.org/10.3892/ or_00000690

53. Zhang Z, Lu J, Guo G, Yang Y, Dong S, Liu Y, et al. IKBKE promotes glioblastoma progression by establishing the regulatory feedback loop of IKBKE/YAP1/miR-Let-7b/i. Tumor Biol. 2017;39(7):101042831770557. https://doi. org/10.1177/1010428317705575

54. Ouyang Y-B, Lu Y, Yue S, Giffard RG. miR181 targets multiple Bcl-2 family members and influences apoptosis and mitochondrial function in astrocytes. Mitochondrion. 2012;12(2):213219. https://doi.org/10.1016/j.mito.2011.09.001 
55. Wang F, Sun J-Y, Zhu Y-H, Liu N-T, Wu Y-F, $\mathrm{Yu}$ F. MicroRNA-181 inhibits glioma cell proliferation by targeting cyclin B1. Mol Med Rep. 2014;10(4):2160-2164. https://doi.org/10.3892/ $\mathrm{mmr} .2014 .2423$

56. Chen H, Huang Q, Dong J, Zhai D-Z, Wang A-D, Lan Q. Overexpression of CDC2/CyclinB1 in gliomas, and $\mathrm{CDC}_{2}$ depletion inhibits proliferation of human glioma cells in vitro and in vivo. BMC Cancer. 2008;8:29. https://doi. org/10.1186/1471-2407-8-29

57. Huang S-X, Zhao Z-Y, Weng G-H, He X-Y, Wu C-J, Fu C-Y, et al. Upregulation of miR-181a suppresses the formation of glioblastoma stem cells by targeting the Notch2 oncogene and correlates with good prognosis in patients with glioblastoma multiforme. Biochem Biophys Res Commun. 2017;486(4):1129-1136. https://doi. org/10.1016/j.bbrc.2017.04.008

58. Xu P, Zhang A, Jiang R, Qiu M, Kang C, Jia Z, et al. The different role of Notch1 and Notch2 in astrocytic gliomas. PLoS One. 2013;8(1):e53654. https://doi.org/10.1371/journal.pone.0053654

59. Chen G, Zhu W, Shi D, Lv L, Zhang C, Liu P, et al. MicroRNA-181a sensitizes human malignant glioma U87MG cells to radiation by targeting Bcl2. Oncol Rep. 2010;23(4):997-1003. https://doi. org/10.3892/or_00000725

6o. Jia G, Wang Q, Wang R, Deng D, Xue L, Shao N, et al. Tubeimoside-1 induces glioma apoptosis through regulation of Bax/Bcl-2 and the ROS/ Cytochrome C/Caspase-3 pathway. Onco Targets Ther. 2015;8:303-311. https://doi.org/10.2147/ OTT.S76063

61. Wang J, Sai K, Chen F, Chen Z. miR-181b modulates glioma cell sensitivity to temozolomide by targeting MEK1. Cancer Chemother Pharmacol. 2013;72(1):147-158. https://doi. org/10.1007/soo280-013-2180-3

62. Sun Y, Wang J, Guo C, Sai K, Wang J, Chen $\mathrm{F}$, et al. MiR-181b sensitizes glioma cells to teniposide by targeting MDM2. BMC Cancer. 2014;14(1):611. https://doi.org/10.1186/14712407-14-611

63. Li P, Lu X, Wang Y, Sun L, Qian C, Yan W, et al. MiR-181b suppresses proliferation of and reduces chemoresistance to temozolomide in U87 glioma stem cells. J Biomed Res. 2010;24(6):436-443. https://doi.org/10.1016/S1674-8301(10)60058-9
64. Costa B, Bendinelli S, Gabelloni P, Da Pozzo E, Daniele S, Scatena F, et al. Human glioblastoma multiforme: p53 reactivation by a novel MDM2 inhibitor. PLoS One. 2013;8(8):e72281. https:// doi.org/10.1371/journal.pone.0072281

65. Wang H, Tao T, Yan W, Feng Y, Wang Y, Cai $\mathrm{J}$, et al. Upregulation of miR-181s reverses mesenchymal transition by targeting KPNA4 in glioblastoma. Sci Rep. 2015;5(1):13072. https:// doi.org/10.1038/srep13072

66. Ruan J, Lou S, Dai Q, Mao D, Ji J, Sun X. Tumor suppressor miR-181c attenuates proliferation, invasion, and self-renewal abilities in glioblastoma. Neuroreport. 2015;26(2):66-73. https://doi.org/10.1097/ WNR.0000000000000302

67. He X, Liu Z, Peng Y, Yu C. MicroRNA-181c inhibits glioblastoma cell invasion, migration and mesenchymal transition by targeting TGF- $\beta$ pathway. Biochem Biophys Res Commun. 2016;469(4):1041-8. https://doi.org/10.1016/j. bbrc.2015.12.021

68. Noh M-G, Oh S-J, Ahn E-J, Kim Y-J, Jung T-Y, Jung S, et al. Prognostic significance of E-cadherin and $\mathrm{N}$-cadherin expression in Gliomas. BMC Cancer. 2017;17(1):583. https:// doi.org/10.1186/s12885-017-3591-z

69. Zhao J, Zhang L, Dong X, Liu L, Huo L, Chen H. High Expression of vimentin is associated with progression and a poor outcome in glioblastoma. Appl Immunohistochem Mol Morphol. 2018;26(5):337-344. https://doi.org/10.1097/ PAI.0000000000000420

70. Bryukhovetskiy I, Shevchenko V. Molecular mechanisms of the effect of TGF- $\beta 1$ on U87 human glioblastoma cells. Oncol Lett. 2016;12(2):1581-1590. https://doi.org/10.3892/ ol.2016.4756

71. Zhang W, Zhang J, Hoadley K, Kushwaha D, Ramakrishnan V, Li S, et al. miR-181d: a predictive glioblastoma biomarker that downregulates MGMT expression. Neuro Oncol. 2012;14(6):712-719. https://doi.org/10.1093/ neuonc/noso89

72. Chen L, Shi L, Wang W, Zhou Y. ABCG2 downregulation in glioma stem cells enhances the therapeutic efficacy of demethoxycurcumin. Oncotarget. 2017;8(26):43237-43247. https:// doi.org/10.18632/oncotarget.18018 
73. Gong X, Schwartz PH, Linskey ME, Bota DA. Neural stem/progenitors and glioma stem-like cells have differential sensitivity to chemotherapy. Neurology. 2011;76(13):1126-1134. https://doi. org/10.1212/WNL.obo13e318212a89f

74. Emery IF, Gopalan A, Wood S, Chow K, Battelli $\mathrm{C}$, George J, et al. Expression and function of ABCG2 and XIAP in glioblastomas. $J$ Neurooncol. 2017;133(1):47-57. https://doi.org/10.1007/ S11060-017-2422-Z

75. Wee B, Pietras A, Ozawa T, Bazzoli E, Podlaha $\mathrm{O}$, Antczak $\mathrm{C}$, et al. ABCG2 regulates selfrenewal and stem cell marker expression but not tumorigenicity or radiation resistance of glioma cells. Sci Rep. 2016;6(1):25956. https://doi. org/10.1038/srep25956

76. Gong W, Wang Z, Wan Y, Shi L, Zhou Y. Downregulation of ABCG2 protein inhibits migration and invasion in U251 glioma stem cells. Neuroreport. 2014;25(8):625-632. https://doi. org/10.1097/WNR.0000000000000161
77. Wang X, Wang E, Cao J, Xiong F, Yang Y, Liu H. MiR-145 inhibits the epithelial-to-mesenchymal transition via targeting ADAM19 in human glioblastoma. Oncotarget. 2017;8(54):9254592554. https://doi.org/10.18632/oncotarget.21442

78. Dong L, Li Y, Han C, Wang X, She, Zhang H. miRNA microarray reveals specific expression in the peripheral blood of glioblastoma patients. Int $J$ Oncol. 2014;45(2):746-756. https://doi. org/10.3892/ijo.2014.2459

79. Cao F, Zhang Q, Chen W, Han C, He Y, Ran Q, et al. IL-6 increases SDCBP expression, cell proliferation, and cell invasion by activating JAK2/STAT3 in human glioma cells. Am J Transl Res. 2017;9(10):4617-4626.

80. Raychaudhuri B, Vogelbaum MA. IL-8 is a mediator of NF- $\mathrm{KB}$ induced invasion by gliomas. $J$ Neurooncol. 2011;101(2):227-235. https://doi. org/10.1007/s11060-010-0261-2 